\title{
Siracusa entre Roma e Cartago durante a Segunda Guerra Púnica*
}

\section{Syracuse among Rome and Carthage in the Second Punic War}

\author{
MATHEUS COUTINHO FIGUINHA \\ Mestre pela Universidade Estadual de Campinas (Unicamp) \\ Doutorando pela Scuola Normale Superiore, Pisa \\ Piazza dei Cavalieri, 7 - 56126 - Pisa, Itália \\ figuinha@yahoo.com
}

\begin{abstract}
RESUMO Desde o aparecimento da tese de Numa Denis Fustel de Coulanges sobre a aliança das aristocracias gregas a Roma (1858), a historiografia tem enfatizado, com relação às cidades siciliotas durante a Segunda Guerra Púnica, uma filiação unilateral da aristocracia a Roma e da plebe a Cartago. A partir do caso de Siracusa, procuramos entender quais eventos levaram a uma aliança ora com Roma, ora com Cartago, e quais eram as personagens envolvidas e seus interesses para saber até que ponto a tese de Fustel se sustenta. A análise é dividida em duas partes, antes e depois do assassinato do tirano Jerônimo.
\end{abstract}

Palavras-chave Segunda Guerra Púnica, Siracusa, aristocracia

Artigo recebido em: 04/11/2009. Aprovado em: 06/07/2010. 
ABSTRACT Since the appearance of Numa Denis Fustel de Coulanges's thesis about the alliance of the Greek aristocracies to Rome (1858), historiography has been emphasizing, regarding the Sicilian cities during the Second Punic War, a unilateral filiation of the aristocracy to Rome and the plebs to Carthage. Taking the case of Syracuse, we try to understand which events led to an alliance either with Rome or Carthage, who were the characters involved and what were their interests in order to evaluate the sustainability of Fustel's thesis. The analysis is divided in two parts, before and after the murder of the tyrant Hieronymus.

Keywords Second Punic War, Syracuse, aristocracy

O tema deste artigo é a aliança entre Roma e as aristocracias das cidades gregas da Sicília durante a Segunda Guerra Púnica (218-201 a.C.). O primeiro a abordá-lo foi Numa Denis Fustel de Coulanges, em seu pouco conhecido Polybe ou la Grèce conquise par les romains, originalmente publicado em 1858. Neste livro, ele sustenta que, em todas as cidades gregas, a aristocracia apoiava Roma, enquanto o povo, apoiava Felipe, que mantinha um governo democrático na Macedônia. Especificamente sobre a Magna Grécia, escreveu que "Pendant la seconde guerre punique, si quelques villes italiennes restèrent fidèles au Sénat, c'est qu'elles lui furent conservées par l'aristocratie. Dans toutes, il y avait deux partis; dans toutes, le peuple était pour Annibal et les riches pour Rome.". Para Fustel, a Grécia era uma nação, cujo problema, ao tempo de Políbio, era a desunião de suas cidades. Ou melhor, a Grécia era dividida em dois partidos, um aristocrático, o outro popular. Ricos e pobres representavam lados opostos em tempos de guerra civil: "les pauvres veulent acquérir la richesse, les riches la conserver ou la reprendre". ${ }^{2}$ De um lado, a aristocracia mostrou-se prontamente devota aos romanos porque estaria convencida de que em Roma governava a aristocracia: não se ouvia falar sobre as lutas internas, já que elas eram resolvidas no foro; a política externa era controlada pelo senado; e era o senado que havia concebido e posto em prática a conquista universal. De outro lado, os romanos favoreceram a aristocracia nas cidades gregas porque tinham interesses na manutenção da tranquilidade.

Uma suposta filiação política da aristocracia a Roma e do povo a Felipe em toda a Grécia - ou a Aníbal em toda a Magna Grécia, - considerada em termos gerais como o faz Fustel, pode parecer um tanto simplista e esque-

1 FUSTEL DE COULANGES, N. D. Polybe ou la Grèce conquise par les romains. Amiens: T. Jeunet, 1858, p.49-50.

2 FUSTEL DE COULANGES, N. D. Polybe ou la Grèce conquise par les romains, p.9. 
mática. Mas, até onde pude perceber, ela tem sido repetida, ao menos com relação à Magna Grécia durante a guerra anibálica, com muita frequência e sem muitas hesitações. ${ }^{3}$ Alguns estudos, porém, valem ser mencionados aqui. Discutindo o desenvolvimento das relações de clientela na política externa romana em seu Foreign Clientelae, E. Badian levanta a questão se de fato havia, durante a Segunda Guerra Púnica, uma afinidade política entre as "upper classes" a favor de Roma e as "lower classes" a favor de Aníbal. ${ }^{4}$ O autor supõe que fosse um mito inventado no século II a.C. para apoiar a aristocracia na Itália. Sua cautela deriva das passagens XXIII.30.8 (Locri), XXIV.47.6 (Arpi), e XXIV.13.3 (Taranto) do próprio Tito Lívio que contradiriam XXIII.14.7, XXIV.13.8 (Nola) e XXIV.2.8 (Crotone), na qual se encontra sua famosa asserção de que "Vnus uelut morbus inuaserat omnes Italiae ciuitates ut plebes ad optimatibus dissentirent, senatus Romanis faueret, [et] plebs ad Poenos rem traheret".

G. E. M. De Ste. Croix, em The class struggle in the Ancient Greek World, a partir de uma perspectiva marxista sustenta, grosso modo, a mesma tese de Fustel. O estudioso dedica-se especificamente à questão da aliança das cidades gregas da Magna Grécia durante a Segunda Guerra Púnica no apêndice deste seu livro. ${ }^{5}$ Em princípio, retoma os casos de Crotone e Nola, que confirmariam o apoio da aristocracia a Roma e da plebe a Aníbal. Em seguida, discutindo com Badian, considera que a passagem XXIII.30.8, relativa a Locri, na qual Lívio indica que a multitudo foi traída pelos principes, não se sustenta pela narrativa mais detalhada do livro seguinte (XXIV.1.2-13). De Ste. Croix alude, especialmente, a XXIV.1.5-7, na qual Lívio menciona a assembléia de todos os cidadãos que acabou decidindo pelo apoio a Cartago, para afirmar que a decisão de mudar de partido na cidade foi "virtually unanimous". E lembra também de XXIX.6.5, na qual principes locrenses encontravam-se entre os romanos em Reggio Calabria em 205, expulsos de Locri pelo partido oposto, que havia entregado a cidade a Aníbal. Com relação a Arpi e Taranto, De Ste. Croix afirma que Badian foi "well beyond the evidence". A declaração dos arpinenses não poderia ser levada ao pé da letra, pois eles queriam afastar a culpa de si diante dos vitoriosos romanos. No caso de Taranto, XXIV.13.3 seria um "mere report" da afirmação de cinco jovens tarantinos feita a Aníbal de que a plebe, que governava a cidade mas que era in potestate iuniorum, o apoiava. Sobre a narrativa da captura da cidade pelo cartaginês (XXV.8-10) e da recaptura por Fábio Máximo (XXVII.15-16), escreve o autor: "I see no sign of any pro-

3 Cf. COSTABILE, F. I "Principes Locrensium" e l'atteggiamento filoromano delle aristocrazie italiote nella tradizione liviana (216-205 a.C.). Historica. Rivista trimestrale di cultura, Reggio Calabria, v.30, fasc.4, p.179-187, 1977, para uma bibliografia relativa ao caso de Locri, ao qual nos dedicaremos um pouco mais adiante. Não conheço outros estudos que abordam sistematicamente casos diversos

4 BADIAN, E. Foreign clientelae (264-70 B.C.). Oxford: Clarendon Press, 1958, p.147-148.

5 DE STE. CROIX, G. E. M. The class struggle in the Ancient Greek world. Londres: Duckworth, 1981, p.519-521. 
Roman feeling on the part of the common people". ${ }^{6}$ Já Siracusa seria um forte exemplo de como a plebe era hostil a Roma, ainda que "certain nobilissimi uiri" fossem a favor de Roma, tendo se entregado a Marcelo em 214.

A partir dos exemplos citados por Badian e De Ste. Croix é difícil aceitar, no meu ponto de vista, a tese de filiações partidárias unilaterais de classes antagonistas durante a Segunda Guerra Púnica. No texto de Lívio, os eventos relacionados a cada uma das cidades mencionadas acima parecem-me ainda mais complicados do que estes estudiosos dão a entender. Em Nola, de fato, o senatus ac maxime primores eius era favorável a Roma, enquanto que toda a plebe queria passar para a parte de Aníbal (XXIII.14.7; cf. XXIII.39.7 e XXIV.13.8). Contudo, tal desejo da plebe não se mostrava tanto por filiação política ou antagonismo de classes, quanto pelo forte receio de que o assédio do exército do cartaginês à cidade levasse à destruição dos campos e a um período de grandes sofrimentos (XXIII.14.7). Devemos também nos lembrar do caso de L. Bâncio, que inicialmente queria entregar a cidade a Aníbal por consideração ao tratamento que recebeu da parte do cartaginês ao ter sido encontrado bastante ferido após a batalha de Cannae. Mas, depois do reconhecimento de sua vigorosa participação a favor dos romanos da parte do praetor Marcelo Cláudio, Bâncio volta a favorecer os romanos (XXIII.15.7-16.1).

O caso de Locri tem chamado a atenção de alguns historiadores italianos (não citados por De Ste. Croix) por causa da suposta contradição entre os capítulos XXIII.30.8 e XXIV.1.7, de Lívio. Na primeira passagem, são os principes a trair a multitudo. No início do vigésimo quarto livro, porém, Lívio descreve a rendição de Locri aos cartagineses com alguns detalhes. Uma multidão de pessoas de todas as idades e ordens sociais (permixtam omnium aetatium ordinumque multitudinem), que recolhia provisões nos campos ao redor da cidade, ao ser surpreendida pela cavalaria de Amílcar, dispersa-se e fica para fora das muralhas. Amílcar desejava negociar a rendição da cidade com os principes, que, antes de qualquer decisão, preferem consultar o populus. É realizada uma assembléia (contio), na qual a maioria decide a favor dos cartagineses. Os principes mencionados por Lívio em ambos os passos são tradicionalmente interpretados como sendo principes plebis, de modo a concordar com a já citada asserção de XXIV.2.8. Felice Costabile, todavia, sugere que principes devam ser reconhecidos como optimates. Seu principal argumento é que as circunstâncias contingentes relatadas em XXIV.1 (os muitos reféns capturados pelos cartagineses) induziram os optimates a se dividirem em dois partidos, um filo-romano e outro filo-cartaginês. ${ }^{7}$ Segundo o estudioso, porém, o caso de Locri não

6 DE STE. CROIX, G. E. M. The class struggle in the Ancient Greek world, p.520

7 COSTABILE, F. I "Principes Locrensium" e l'atteggiamento filoromano delle aristocrazie italiote nella tradizione liviana (216-205 a.C.), esp. p.181-183. 
contradiria a asserção de Lívio. ${ }^{8}$ A divisão dos optimates em dois partidos é bastante convincente, mas, a meu ver, não há contradição somente se o caso de Locri for pensado isoladamente. Se, ao contrário, o considerarmos junto com os outros casos levantados pela historiografia e apresentados ou discutidos aqui, a asserção liviana deve ao menos ser nuançada.

Com relação a Arpi e Taranto, não vejo porque Badian teria forçado as evidências. Lívio não afirma nem deixa a entender que a declaração dos arpinenses de que foram os principes a entregar a cidade a Aníbal fosse dúbia por causa de quaisquer que fossem os motivos (XXIV.47.6). Os quinque nobiles iuuenes de Taranto que desejavam entregar a cidade ao cartaginês faziam-no também por reconhecimento ao tratamento que receberam ao serem capturados em parte após a batalha do lago Trasimeno, em parte após a batalha de Cannae (XXIV.13.2; cf. XXV.8-11). Antes de se encontrarem com Aníbal, eles já haviam convencido a maioria dos jovens da cidade a apoiar a troca para o lado dos cartagineses. Que a plebe governasse a cidade e desse a decisão final a favor da troca não me parece um indício de que houvesse filiações opostas a partir de lutas de classes.

Acredito que Claude Nicolet tenha razão ao assinalar que não se pode atribuir a Aníbal uma ideologia política. Como lembra o autor, a historiografia antiga tinha a tendência geral de difamar os adversários, e Políbio e Lívio fizeram-no com as palavras "democrático" e "popular". Ao mesmo tempo, aponta outros casos em que Lívio teria contradito a si mesmo: em Cápua, a plebe e quase todo o senado fizeram-se a favor de Aníbal (XXIII.2-7); este, enquanto assediava Nocera, tentou em vão atrair para a sua parte seja a plebe, sejam os principes (XXIII.15.3); com relação às cidades etruscas, foi o senado de Arezzo a concorrer contra os romanos (XXVII.24). ${ }^{9}$ Nicolet sugere apenas - infelizmente não se deteve nesta ideia - que "Souvenirs de l'indépendance, haines locales ou simple opportunisme ont joué autant, sinon beaucoup plus, que les soi-disant sympathies 'politiques' pour Hannibal". ${ }^{10}$

A minha intenção, portanto, é seguir no caminho indicado por Nicolet, tentando entender quais elementos jogaram na escolha das cidades sici-

8 COSTABILE, F. I "Principes Locrensium" e l'atteggiamento filoromano delle aristocrazie italiote nella tradizione liviana (216-205 a.C.), p.181 e 184.

9 NICOLET, C. Les guerres puniques. In: Rome et la conquête du monde méditerranéen, 264-27 avant J.-C. Genèse d'un empire. Paris: Presses Universitaires de France, v.2, 1978, p.617-618. Capua é de fato um caso onde o nacionalismo, somado à derrota dos romanos em Cannae, parece ter tido forte influência na decisão de trocar por Aníbal: "Ab hac oratione consulis dimissis redeuntibusque domum legatis unus ex iis Vibius Virrius tempus venisse ait, quo Campani non agrum solum ab Romanis quondam per iniuriam ademptum recuperare, sed imperio etiam Italiae potiri possint; foedus enim cum Hannibale quibus uelint legibus facturus; neque controuersiam fore, quin, cum ipse confecto bello Hannibal uictor in Africam decedat exercitumque deportet, Italiae imperium Campanis relinquatur" (XXIII.6.1-2). Embora a figura de Pacúvio Calávio, nobilis idem ac popularis homo, possa nuançar ainda mais a situação na cidade (XXIII.3-4). Além dos casos já citados pela historiografia, podemos lembrar também de Enna, onde são os principes que tentam entregar o forte romano a Imilcão (XXIV.37.5).

10 NICOLET, C. Rome et la conquête du monde méditerranéen, 264-27 avant J.-C. Les structures de l'Italie romaine. Paris: Presses Universitaires de France, v.1, 1977, p.282. 
lianas a favorecer Roma ou Cartago. A leitura da terceira década de Lívio junto com o artigo de Patrich Marchetti sobre a Segunda Guerra Púnica na Sicília atraiu minha atenção para os eventos de Siracusa. ${ }^{11}$ Siracusa é reconhecidamente um caso em que a aristocracia favoreceu Roma, a plebe, Cartago, ${ }^{12}$ mas, ao procurar determinar a sucessão dos eventos dos anos 215 e 214 através do texto de Lívio, Marchetti deixa entrever alguns dos momentos incertos de uma aliança ora com Cartago, ora com Roma. Além disso, os esforços diplomáticos de ambas as partes em conflito nos dá uma ideia da importância da cidade durante a guerra.

Acredito, assim, que existam elementos suficientes para uma investigação do caso de Siracusa. Nas páginas seguintes, destacarei quais foram os eventos ocorridos na cidade entre 215 e 214 que levaram a uma aliança ora com Roma, ora com Cartago. Tentarei, sempre quando possível, identificar os grupos filo-romano e filo-cartaginês com precisos estratos políticos e sociais, e esclarecer quais eram os interesses em jogo destes grupos. Recorrerei a Políbio e, sobretudo, a Lívio, que nos fornecem as narrativas mais detalhadas e lineares que foram conservadas.

\section{Jerônimo entre Roma e Cartago}

Políbio e Tito Lívio têm versões diversas com relação à atuação do tirano Jerônimo na decisão de estabelecer uma aliança com Cartago. Ambos o caracterizam como volúvel, ${ }^{13}$ mas, enquanto que para Políbio ele teve uma participação relativamente ativa, para Lívio ele não foi que um fantoche nas mãos de seu tio Adranodoro. Vejamos os dois relatos separadamente.

Políbio inicia a narrativa dos eventos da Sicília em seu sétimo livro com o envio de embaixadores a Aníbal da parte de Jerônimo, que teria sido convencido a fazê-lo por seus tios, Adranodoro e Zóipo (VII.2.1). Em seguida, porém, ambos saem de cena e deixam o palco ao sobrinho. Aníbal recebe afavelmente a embaixada e a reenvia acompanhada pelo cartaginês Aníbal, capitão de Trirreme, e por dois irmãos nascidos em Cartago, mas siracusanos de origem, Hipócrates e Epicides. Jerônimo, ao ouvir a dele-

11 MARCHETTI, P. La deuxième guerre punique en Sicile: les années 215-214 et le récit de Tite-Live. Bulletin de l'Institut Historique Belge de Rome, Roma/Paris/Bruxelas, v.42, p.5-26, 1972.

12 Cf. BERVE, H. König Hieron II. Munique: Verlag der bayerischen Akademie der Wissenschaften, 1959, p.86-99; o próprio MARCHETTI, P. La deuxième guerre punique en Sicile: les années 215-214 et le récit de Tite-Live, p.25; e o manual de BRACCESI, L. e MILLINO, G. La Sicilia greca. Roma: Carocci, 2000, p.191-196. O livro de MEIERWELCKER, H. Karthago, Syrakus und Rom: zu Grundfragen von Frieden und Krieg. Göttingen: Musterschmidt, 1979, apesar do título promissor, é muito sintético e deixa a desejar. Para um período anterior ao nosso, vale a pena ver, além do livro de Berve, o de ROUSSEL, D. Les siciliens entre les romains et les carthaginois à l'époque de la première guerre punique. Essai sur I'histoire de la Sicile, p.276-241. Paris: Les Belles Lettres, 1970.

13 As imagens de Jerônimo transmitidas por Políbio e Lívio são bastante negativas, embora o primeiro seja mais cauto em seu julgamento. Políbio caracteriza o jovem rei como instável e impulsivo (VII.4.6 e 8), enquanto Lívio o define como moralmente viciado (XXIV.4.1-2), soberbo (XXIV.5.3-5), violento (XXIV.5.6), instável e arrogante (XXIV.6.9). 
gação cartaginesa, mostra-se "imediatamente disposto" a cooperar com Aníbal (VII.2.5). Notemos que as disposições de colaborar eram apenas de Jerônimo.

Informado destes fatos, o pretor ( $\sigma \tau \varrho \alpha \tau \eta \gamma$ ćs) Ápio Cláudio envia embaixadores a Siracusa para renovar os tratados de aliança assinados com Jerão, avô de Jerônimo. Os emissários romanos ressaltam que seria do interesse do próprio Jerônimo manter a aliança com Roma e referem-lhe o caso no qual, tendo ouvido sobre a morte de seu avô, haviam enviado navios em direção à cidade porque temiam que os siracusanos não aprovassem seu governo, já que ele era ainda muito jovem - quando de fato assumiu o poder, pouco tempo depois, tinha apenas quinze anos. Mas os romanos, sendo informados que Jerão ainda estava vivo, recuaram (VII.3.6).

Jerônimo, portanto, sabia muito bem dos benefícios que podia tirar de uma aliança com Roma. O apoio oferecido pelos romanos ser-lhe-ia importante para manter-se no trono, sobretudo pelo fato de que seu governo não tinha sido bem recebido pelos cidadãos, ${ }^{14} \mathrm{e}$, dado o histórico das lutas políticas nas cidades gregas da Sicília, ${ }^{15}$ uma conjura contra ele não seria surpreendente (como de fato aconteceu). A fragilidade de seu governo pode ser também presumida pelo fato de que ele tinha acabado de enviar a Alexandria seus irmãos mais jovens ou ilegítimos (VII.2.1), talvez para evitar uma disputa pelo trono. ${ }^{16}$ Os romanos haviam deixado claro que lhe dariam auxílio, como haviam feito a seu avô. Mas ele escolheu aliar-se a Cartago justamente porque tinha sido informado das extraordinárias vitórias de Aníbal na Itália, em especial da batalha de Cannae, e esperava uma derrota de Roma na guerra. O auxílio de uma Roma prestes a ser derrotada não seria de nenhuma utilidade. Trata-se, portanto, de um claro oportunismo da parte de Jerônimo, de uma tentativa de se aproveitar da situação favorável aos cartagineses. Estes, pensava, certamente venceriam a guerra. Eis suas palavras, tais como as escreveu

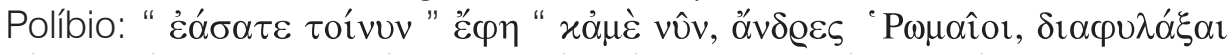

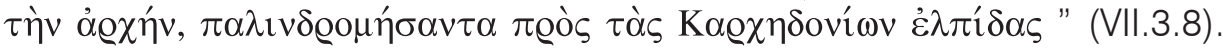

O oportunismo de Jerônimo é ainda mais evidente quando lemos que ele buscava a ajuda dos cartagineses não só para se manter no trono, mas também para alargar seus domínios. As condições do tratado discutidas em Cartago explicam bem este ponto. De acordo com Políbio:

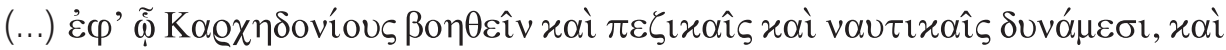

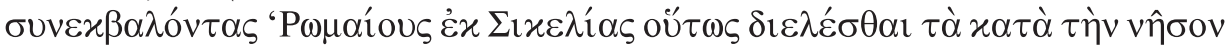

14 T. L. XXIV.4.6-7: "Cum expirasset [Jerão] tutores testamento prolato pueroque in contionem produco - erat autem quindecim tum ferme annorum - paucis, qui per contionem ad excitandos clamores dispositi erant, adprobantibus testamentum, ceteris uelut patre amisso in orba ciuitate omnia timentibus".

15 Cf. BERGER, S. Revolution and Society in Greek Sicily and Southern Italy. Stuttgart: F. Steiner, 1992.

16 Cf. WALBANK, F. W. A historical commentary on Polybius. Commentary on books VII-XVIII. Oxford: Oxford University Press, 1967, v.2, p.32, para as possíveis motivações de Jerônimo de enviar seus irmãos, junto com Zóipo, a Alexandria. 


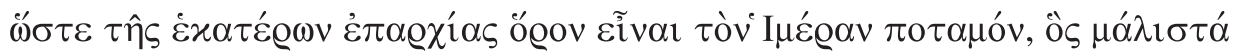

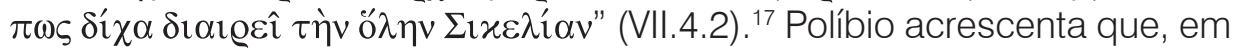
seguida, Hipócrates e Epicides instigam o tirano dizendo que ele teria o direito de dominar toda a Sicília. Jerônimo, assim, envia uma outra embaixada a Cartago para modificar as cláusulas territoriais, de modo que, em troca da ajuda de Siracusa na Itália, ele mantivesse o domínio de toda a ilha e que os cartagineses o ajudassem a expulsar os romanos de lá. ${ }^{18}$

É possível que as sugestões de Hipócrates e Epicides, como sugere Marchetti, derivassem das hesitações do tirano de romper a aliança com os romanos e engajar-se na guerra. ${ }^{19}$ Se foi este realmente o caso, então os irmãos souberam satisfazer os interesses de Jerônimo, por mais absurdos que fossem, fazendo com que ele tomasse uma decisão. Na narrativa de Políbio, porém, a tentativa do tirano de fazer valer seus interesses pessoais coexiste com a influência dos irmãos. Jerônimo teria superado suas hesitações não só por causa do que lhe era oferecido, mas também por causa de quem Ihe oferecia. Seu desejo de dominar toda a Sicília estava ligado ao seu fascínio pelas histórias que Hipócrates e Epicides haviam Ihe contado sobre a atuação militar de Aníbal na Itália. Quanto a Adranodoro, ele é mencionado de novo por Políbio somente quando Jerônimo consulta seus conselheiros se devia ou não declarar guerra contra os romanos. Adranodoro, ao contrário dos outros conselheiros, demonstra-se favorável, pois seria uma oportunidade única para Jerônimo de estabelecer sua soberania sobre a ilha (VII.5.4). Mas a decisão final de aliar-se a Cartago, o tirano a tomou somente após ter ouvido o parecer de Hipócrates e Epicides.

Tito Lívio insiste ainda mais do que Políbio na volubilidade de Jerônimo, mas seriam outros a influenciá-lo. Antes da morte do tirano, Lívio menciona Hipócrates e Epicides apenas duas vezes. Assim, oferece elementos diferentes, destacando personagens que não podemos excluir da nossa análise.

Lívio começa a falar de Jerônimo indicando que tutores e amigos aproveitavam-se da sua jovem idade e da sua índole (XXIV.4.2). Jerão, sabendo disso, queria deixar Siracusa livre ao fim da vida, mas foi convencido pelas insistentes sugestões das filhas Damarata e Heráclia a deixar Jerônimo como seu herdeiro. Lívio sublinha a ambição das duas mulheres: "Huic consilio eius [de Jerão] summa ope obstitere filiae, nomen regium penes puerum futurum ratae, regimen rerum omnium penes se uirosque suos Adran

17 Segundo WALBANK, F. W. A historical commentary on Polybius. Commentary on Books VII-XVIII, v.2, p.34, naquela época existiam dois rios na Sicília com o nome de Imera, "and ancient tradition made the two rivers rise from a single spring and so form virtually one stream dividing Sicily". Trata-se dos hodiernos Grande e Salso.

18 BERVE, H. König Hieron II., p.91-92, sustenta que os relatos de Políbio (VI.4.4-9) e Lívio (XXIV.6.8-9) a respeito são essencialmente confiáveis. FINLEY, M. I. Ancient Sicily to the arab conquest. Londres: Chatto \& Windus, 1968, p.117, supõe que Cartago tenha aceitado de má fé as condições territoriais de Jerônimo.

19 MARCHETTI, P. La deuxième guerre punique en Sicile: les années 215-214 et le récit de Tite-Live, p.8. 
<odorum et Zoïppum, qui tut> orum primi reliquebantur" (XXIV.4.3). Eis um dado importante na narrativa de Lívio: Adranodoro e Zóipo eram considerados os primeiros tutores de Jerônimo. O que significa que, sendo o jovem tirano totalmente influenciado pelos seus tutores, seriam eles que teriam o poder depois da morte de Jerão. E Adranodoro mostra sua predominância dispensando todos os outros tutores que Jerão havia deixado responsáveis por Jerônimo (XXIV.4.9).

Adranodoro, Zóipo e um certo Trasão eram os poucos que conseguiam ter acesso ao tirano. Os dois primeiros defendiam uma aliança com Cartago, enquanto que Trasão era o único favorável aos romanos. Este, contudo, é tirado de cena após ser falsamente incriminado em uma conjura contra Jerônimo (XXIV.5). Helmut Berve levanta a hipótese de que a conjura tenha sido planejada pela oligarquia favorável aos romanos. ${ }^{20}$ De fato, a revelação do nome de Trasão por Teodoto não deve ter sido tão fortuita quanto Lívio nos dá a entender, mas não temos como realmente o saber com as fontes que temos à disposição. É só então, quando não havia mais o estímulo para a aliança com Roma representado por Trasão, que Lívio conta que foram enviados embaixadores a Aníbal (XXIV.6.2), e este dado coincide com Políbio. De fato, as informações fornidas por Lívio deste ponto até o envio da segunda delegação siracusana a Cartago coincidem perfeitamente com Políbio. ${ }^{21}$

Embora Lívio mencione que Adranodoro, Zóipo e Trasão não fossem nem mesmo eles muito escutados "sobre outras coisas" (XXIV.5.7), não deixa dúvidas com relação à influência preponderante do primeiro. Tal situação mostra-se mais evidente quando, um pouco mais adiante, no mesmo livro, lemos que Zóipo tinha sido enviado como embaixador ao rei Ptolomeu, em Alexandria, e lá permanecido em exílio voluntário (XXIV.26.1). Sobre Heráclia, sua esposa, escreveu Lívio: "nihil se ex regno illius [de Jerônimo] praeter exsilium uiri habere; neque fortunam suam eamdem uiuo Hieronymo fuisse quam sororis neque interfecto eo causam eamdem esse. Quid quod, si Adranodoro consilia processissent, illa cum uiro fuerit regnatura, sibi cum ceteris seruiendum?" (XXIV.26.4-5). Na narrativa de Lívio, portanto, é evidente a manobra de Adranodoro para afastar Zóipo de Siracusa. E se este foi enviado a Alexandria ao mesmo tempo em que a primeira embaixada siracusana a Aníbal, toda a negociação para se aliar a Cartago foi conduzida por Adranodoro. Lívio não menciona diretamente a influência de Hipócrates e Epicides como o faz Políbio. Jerônimo, quando decidiu enviar uma segunda embaixada a Cartago para tentar alterar a cláusula territorial, teria sido persuadido "adsentationibus eorum qui eum non Hieronis tantum sed Pyrrhi

20 BERVE, H. König Hieron II., p.87.

21 Cf. PAL, J. Introduction. In: TITO LíVIO. Histoire romaine. Livre XXIV. Paris: Les Belles Lettres, 2004, vol.14, p.X-xii, para uma comparação da narrativa de Lívio com a de Políbio com relação aos eventos de Siracusa. 
etiam regis, materni aui, iubebant meminisse" (XXIV.6.8), sem especificação de quem o teria feito. Talvez Lívio quisesse enfatizar a avidez pelo poder de Adranodoro. E um outro ponto ainda, Lívio não menciona as discussões partidárias dos conselheiros do tirano que tiveram lugar antes da decisão final de declarar guerra contra os romanos. Desse modo, a aliança com Cartago, uma vez decidida a mudança, é feita sem contratempos, possivelmente porque a aliança com Roma era incompatível com as ambições do poder de Adranodoro. Mas retornaremos logo a este ponto.

Tanto Hipócrates e Epicides quanto Adranodoro sem dúvida tiveram grande importância na decisão final de se aliar a Cartago, embora seja difícil saber quem realmente exerceu a maior influência sobre Jerônimo. Mas talvez devêssemos conceder ao tirano uma certa autonomia, pelo menos a de escolher por qual lado se deixar influenciar. Uma aliança com Cartago de fato poderia Ihe trazer enormes vantagens territoriais, o que com Roma era impossível. ${ }^{22}$ De qualquer modo, seja em Políbio, seja em Lívio, todas as tratativas de um acordo com Cartago são realizadas na corte real. A plebe não teve nenhuma participação. Nada nos permite falar, ao menos por enquanto, de divisões partidárias entre a aristocracia e a plebe a favor de Roma ou Cartago.

\section{Siracusa entre Roma e Cartago após o assassinato de Jerônimo}

Para os eventos de Siracusa após o assassinato de Jerônimo, ocorrido no início de $214,{ }^{23}$ contamos apenas com o relato de Tito Lívio. Adranodoro continua a ser uma das personagens centrais e sua avidez pelo poder torna-se ainda mais clara. Sua primeira atitude ao saber do assassinato do sobrinho foi refugiar-se na ilha de Ortigia, talvez na esperança de substituí10. ${ }^{24}$ Contudo, no dia seguinte se submete às deliberações do senado e do povo siracusano - isto é, abre as portas da ilha e entrega a fortificação (XXIV.22.4) - porque estava convencido da possibilidade de chegar ao poder por uma "via mais segura", caso cedesse às circunstâncias (XXIV.22.11). De fato, na assembléia (comitia praetoribus creandis) do dia seguinte, ele foi eleito praetor entre os primeiros (XXIV.23.2). Lívio sublinha o ciuium consensus das decisões tomadas nos primeiros dias após a morte de Jerônimo (XXIV.22-23.4).

22 Pol. VII.5.7-8: Jerônimo exige, para respeitar o tratado com os romanos, que eles reconheçam seu domínio até o rio Imera, como nas condições territoriais do primeiro tratado do tirano com Cartago. Os romanos obviamente se negam a fazê-lo e é declarada guerra.

23 Cf. MARCHETTI, P. La deuxième guerre punique en Sicile: les années 215-214 et le récit de Tite-Live, p. 15, para a datação. É possível que a oligarquia filo-romana tenha tido participação na conjura contra Jerônimo, e que um dos motivos tenha sido a aliança com Cartago. A este respeito, BERVE, H. König Hieron II., p.94. Mas afirmá-lo é ir além das evidências. Berve parte da tese de que a aristocracia foi sempre favorável a Roma. Veja também a discussão de MARCHETTI, P. La deuxième guerre punique en Sicile: les années 215-214 et le récit de Tite-Live, p.10, n.3.

24 BERVE, H. König Hieron II, p.90, 95 e 98; MARCHETTI, P. La deuxième guerre punique en Sicile, p.15. 
Em seguida, contudo, Hipócrates e Epicides começam a mobilizar os soldados, os desertores, que provinham substancialmente dos marinheiros aliados dos romanos, e pessoas da infima plebs contra o senado e os optimates (XXIV.23.10). Como difundiam os irmãos, estes tramavam secretamente, com o pretexto de uma reconciliação, a defecção de Siracusa aos romanos, de modo que a cidade fosse dominada pela factio ac pauci auctores que promoviam a dita reconciliação. Lívio enfatiza que ambos tiveram sucesso com os soldados porque eles também eram jovens e soldados.

Podemos supor que muitos dos membros da plebe mobilizados por Hipócrates e Epicides foram, naquele primeiro momento, os mesmos que já haviam sido mobilizados por Gelão pouco tempo antes. Gelão era o primogênito de Jerão e, como regente, passou para o lado dos cartagineses logo depois da vitória de Aníbal na batalha de Cannae. Porém, morreu (mors adeo opportuna ... eum ... adsumpsisset) enquanto armava a multitudo e instigava os aliados (XXIII.30.10-12). ${ }^{25}$ É possível que o ânimo dos que eram favoráveis a Cartago na cidade tenha ficado latente depois da morte repentina de Gelão até que encontrasse uma oportunidade de se manifestar. ${ }^{26}$ Mas Lívio não diz que foi toda a plebe mobilizada por Hipócrates e Epicides.

Adranodoro, da sua parte, também procurou aproveitar-se da multidão cada dia maior mobilizada por Hipócrates e Epicides (XXIV.24.1). Adranodoro tinha um plano elaborado com Temisto, marido de Harmonia, uma das filhas de Gelão, para tomar o poder na cidade (XXIV.24.2). A ideia inicial havia surgido alguns anos antes, durante as núpcias de Harmonia e Temisto (XXIV.24.6). Assim, podemos pensar que Adranodoro tivesse sempre sido favorável a uma defecção aos cartagineses, pois a aliança com Roma seria incompatível com suas ambições pelo poder. ${ }^{27}$ É significativo que ele tenha decidido pôr em prática o plano de sua conjura justamente quando imaginava poder contar com o suporte de Epicides e Hipócrates, que, naquele momento, conseguiam mobilizar muitos.

Depois que ambos os irmãos foram eleitos praetores no lugar de Adranodoro e Temisto, começa a desordem em Siracusa. Lívio assim caracterizou a assembléia que os elegeu: "et erat confusa contio non populari modo sed militari quoque turba, magna ex parte etiam perfugis, qui omnia nouare cupiebant, permixtis" (XXIV.27.2). A eleição dos irmãos em uma assembléia composta de outros além dos cidadãos seria ilegítima, mas os praetores não ousaram contrariar a multidão e proclamaram, contra sua vontade, Hipócrates e Epicides praetores. Lívio menciona a esta altura que uma primeira delegação havia sido enviada a Ápio Cláudio para pedir uma trégua de dez dias e, obtida esta, uma segunda para renovar a aliança (XXIV.27.4).

25 Cf. BERVE, H. König Hieron II, p.64-66, para as tensões entre Jerão e o $\delta \tilde{\eta} \mu o \varsigma$.

26 MARCHETTI, P. La deuxième guerre punique en Sicile, p.6.

27 MARCHETTI, P. La deuxième guerre punique en Sicile, p.6. 
O envio da primeira embaixada, portanto, deve ser situado logo após o assassinato de Jerônimo e o envio da segunda, pouco antes da eleição de Epicides e Hipócrates. Ambos se referiam a essas negociações para mobilizar o exército e pessoas da infima plebs. ${ }^{28}$ É bastante provável que um armistício de dez dias antes da negociação do tratado de aliança tenha sido pedido porque hesitações sobre qual lado favorecer se manifestassem entre os próprios praetores.

Marcelo aceita as condições apresentadas pelos emissários siracusanos - mandados a ele por Ápio Cláudio - e envia uma delegação a Siracusa para que se concluísse o tratado com os praetores (XXIV.27.6). Mas, informados de que a frota cartaginesa aproximava-se de Pachino, os irmãos "nunc apud mercennarios milites, nunc apud transfugas prodi Romano Syracusas criminabantur" (XXIV.27.7). As acusações pareceram ainda mais dignas de crédito quando Ápio Cláudio ancorou no porto da cidade navios romanos, com a intenção de encorajar os que eram favoráveis a Roma (XXIV.27.8). E deste modo a multidão "tumultuadamente" impediu o desembarque dos romanos.

Ainda que a eleição de Hipócrates e Epicides representasse uma óbvia ameaça para a aliança com Roma, não podemos afirmar que existisse, naquele momento, um sentimento anti-romano dominante em Siracusa. ${ }^{29} \mathrm{Na}$ assembléia convocada naquele contexto turbulento, os filo-romanos e os filo-cartagineses litigam. Após o discurso de Apolônides, unus principum, os praetores, delecti senatorum, duces ordinum e praefecti auxiliorum decidem manter a paz com os romanos, já que não havia motivo de declarar guerra contra eles (XXIV.28). Por mais que tenha sido uma decisão de alta cúpula, ela não foi tomada que depois de muita discussão.

Nem mesmo a eleição de Hipócrates e Epicides foi bem aceita por todos, em particular pelos outros praetores. O pedido dos leontinos aos siracusanos de uma defesa militar para o seu território foi visto como uma ocasião para se livrar de uma "multidão desordenada e tumultuosa" e de seus líderes (XXIV.29.1). Assim, Hipócrates foi enviado como general dos desertores e de muitos mercenários das milícias auxiliares. Ele, porém, procura dar um motivo de guerra saqueando as zonas limítrofes da província romana e tomando de assalto a guarnição romana que tinha sido enviada para proteger os campos dos aliados (XXIV.29.4). Mas nem mesmo assim inicia o conflito entre Roma e Siracusa. Marcelo envia uma delegação a Siracusa exigindo o afastamento dos irmãos da Sicília, e, nesse momento, Epicides se dirige a Leontini. Lá vigorava um forte sentimento anti-romano, e, assim, a multitudo é facilmente persuadida a não aceitar o tratado concluído entre Siracusa e Roma. Quando os embaixadores siracusanos referem o

28 MARCHETTI, P. La deuxième guerre punique en Sicile, p.19.

29 MARCHETTI, P. La deuxième guerre punique en Sicile, p.15-16. 
fato aos romanos, Roma, auxiliada por Siracusa, parte para o assédio de Leontini (XXIV.29.6-9).

Mas por que os soldados mercenários e os desertores foram desde o início favoráveis a Hipócrates e Epicides? Suponho que os interesses deles eram, antes de tudo, econômicos e militares. Eles já haviam manifestado esperanças de pôr as mãos no tesouro real logo após o assassinato de Jerônimo (XXIV.21.3), e a esposa de Adranodoro, naquela ocasião, havia sugerido ao marido que comprasse sua fidelidade com o mesmo dinheiro (XXIV.22.10). A possibilidade de militar sob o comando de generais mais valorosos também era um fator de peso (XXIV.21.3): as notícias das vitórias de Aníbal eram certamente ouvidas em todos os lugares, e da boca de Hipócrates e Epicides deviam ganhar cores ainda mais intensas. Assim, a meu ver, fica mais fácil entender porque Lívio insiste tanto no fato de que eles, sendo também soldados e jovens, tinham tido facilidade em mobilizar os soldados.

É somente depois da tomada de Leontini pelos romanos que Epicides e Hipócrates conseguem mobilizar quase todos os siracusanos contra Roma. ${ }^{30}$ Conseguem-no, segundo Lívio, através de várias mentiras. Primeiro, enviam um legado ao encontro do exército siracusano que conta, entre notícias verdadeiras, outras falsas, ou seja, que soldados e cidadãos haviam sido massacrados indistintamente e que, como pensava ele, nenhum homem adulto havia sido poupado, que a cidade havia sido saqueada e os bens dos ricos dados aos soldados (XXIV.30.4). Em seguida, os irmãos são acolhidos pelos soldados cretenses, que, sendo mercenários de Siracusa, haviam sido aprisionados entre os soldados romanos na batalha do lago Trasimeno, mas liberados por Aníbal. Acolhendo-os, não obedecem aos praetores quando são ordenados de prendê-los; chega-se ao ponto em que os praetores temem a sua reação (XXIV.31.4). Hipócrates manipula os soldados com outras mentiras ainda: lê-lhes uma carta como se tivesse sido interceptada, mas que a havia escrito ele mesmo, dos praetores siracusanos a Marcelo. Nela, teriam escrito que se deveriam eliminar todos os mercenários (XXIV.31.7-9). Ouvindo isso, os dois praetores que conduziam o exército, assustados, fogem para Siracusa. Os irmãos também tentam enganar os siracusanos e excitá-los contra os romanos, subornando um soldado dentre os que foram assediados em Leontini a fim de que desse notícia dos falsos eventos da tomada da cidade.

Após a difusão da falsa notícia do massacre de Leontini, um sentimento anti-romano se generaliza em Siracusa. De fato, no discurso dos sicilianos contra Marcelo no senado, foi dito: "Eam quoque Hippocratis et Epicydis tyrannidem Marcellum excitasse Leontinis crudeliter direptis" (XXVI.30.4). Não

30 MARCHETTI, P. La deuxième guerre punique en Sicile, p.18. 
só o uolgus acredita no soldado, mas também os senadores (XXIV.32.1). Todos pensavam que o melhor a fazer era fechar as portas e vigiar a cidade, ainda que nem todos temessem ou odiassem os romanos. Prossegue Lívio: "Ad militare genus omne partemque magnam plebis inuisum esse nomen Romanum; praetores optimatiumque pauci, quamquam inflati uano nuntio erant, tamen ad propius praesentiusque malum cautiores esse" (XXIV.32.2-3). Notemos que todos os militares e a maior parte da plebe eram hostis aos romanos, mas não toda a plebe. Os pretores e poucos principais, não todos, estavam mais preocupados com o problema imediato representado por Hipócrates e Epicides do que com os romanos, embora não lhes fossem favoráveis.

Hipócrates e Epicides, a essa altura dos acontecimentos, estavam fora das muralhas da cidade com o exército. E os parentes dos que serviam no exército acabam abrindo as portas. Os praetores procuram todos os modos de intervir, mas a "multidão excitada" não Ihes dá ouvidos. Praetores cum iuuentute popularium refugiam-se na Acradina; mercennarii milites perfugaeque et quidquid regiorum militum Syracusis erat engrossam o exército filo-cartaginês (XXIV.32.7). A Acradina é tomada já no primeiro assalto e os praetores que não conseguem fugir em meio à confusão são assassinados. Acontece, na narrativa de Lívio, uma revolução na cidade: os escravos são libertados, as portas dos cárceres são abertas, e os irmãos são eleitos praetores pela multidão (... confusaque haec omnis multitudo ...) (XXIV.32.9).

Embora Lívio destaque as mentiras de Hipócrates e Epicides, cuja finalidade era de persuadir todos contra os romanos, não é de se excluir que eles também tenham se servido da violência. O líder da delegação siracusana, após a tomada da cidade pelos romanos, disse a Marcelo: "Neque primo - inquit - Syracusani a uobis defecimus, sed Hieronymus, nequaquam tam in uos impius quam in nos, nec postea pacem tyranni caede compositam Syracusanus quisquam, sed satellites regii, Hippocrates atque Epicydes, oppressis nobis hinc metu, hinc fraude turbauerunt" (XXV.29.2-3). O uso da violência, de fato, não parece improvável, visto que os primeiros a serem favoráveis aos irmãos foram os soldados.

A partir das palavras de Lívio, podemos perceber que Hipócrates e Epicides, no fim das contas, conseguiram mobilizar contra os romanos todo o exército, a maior parte da plebe e dos principais. Porém, sabemos que os praetores, poucos dos optimates e a iuuentus popularium permaneceram, se não filo-romanos, mais preocupados com a situação causada pelos irmãos. $O$ fato de que aliqui nobilissimi uiri tivessem sido expulsos de Siracusa por serem favoráveis aos romanos, como conta Lívio no livro seguinte (XXV.23), não contradiz as informações levantadas aqui. Eles poderiam bem ser os poucos optimates anti-cartagineses. Portanto, a meu ver, não se pode afirmar que houvesse nítida distinção política em base a estratos sociais diferentes. 
O retrato que Lívio nos oferece é bem mais nuançado do que uma simples divisão partidária de classes antagonistas.

Lívio, muito frequentemente, associa aos partidários de Hipócrates e Epicides a multitudo, mas este termo é muito vago, e usado sempre de maneira negativa. Lívio sublinha a suposta volubilidade da multidão com breves digressões moralistas: "Ea natura multitudinis est: aut seruit humiliter aut superbe dominatur; libertatem, quae media est, nec struere modice nec habere sciunt; et non ferme desunt irarum indulgentes ministri, qui auidos atque intemperantes suppliciorum animos ad sanguinem et caedes inritent" (XXIV.25.8-9).

Associando a multitudo aos partidários de Hipócrates e Epicides, Lívio procura desacreditá-los. Todas as atitudes dos irmãos teriam apenas um objetivo: afastar os siracusanos da aliança com os romanos. Para alcançar tal objetivo, contavam não mais que mentiras, e é por isso que conseguem convencer a multidão, e não os praetores, porque as paixões daquela eram facilmente inflamadas, embora os senadores também tivessem acreditado neles. De qualquer modo, não há nenhuma escolha partidária da multitudo pela democracia ao apoiar uma aliança com Cartago. Direi que Lívio não lhe oferece nem mesmo essa capacidade, porque ela era irracional e movida por paixões. Os praetores, ao contrário, que tinham a capacidade de perceber as mentiras contadas pelos irmãos porque raciocinavam claramente, ${ }^{31}$ eram filo-romanos. Em suma, a razão leva sempre a apoiar Roma, a mentira e a loucura levam a favorecer os cartagineses, uma característica típica de Lívio. Um outro ponto para finalizar: a multitudo é associada a seditio (XXIV.27.3), um elemento revolucionário, hostil à paz - como a libertação dos escravos e dos encarcerados - que, aos ouvidos da elite romana, era assustador.

\section{Conclusão}

Neste artigo, destacamos quais eventos ocorridos em Siracusa entre os anos 215 e 214 a.C. levaram a uma aliança ora com Roma, ora com Cartago. Procuramos sempre identificar os grupos filo-romano e filo-cartaginês com precisos estratos políticos e sociais e, ao mesmo tempo, esclarecer quais eram os interesses em jogo desses grupos.

Para os eventos anteriores ao assassinato do tirano Jerônimo, no início de 214, contamos com as narrativas de Políbio e Tito Lívio. O primeiro concede a Jerônimo uma participação ativa nas tratativas para estabelecer uma aliança com Cartago, embora sua decisão final tenha sido influenciada por Hipócrates e Epicides, legados de Aníbal em Siracusa. Para o segundo, ao contrário, o tirano não foi que um fantoche nas mãos de seu tio Adranodoro.

31 Veja a racionalidade do discurso de Apolônides, com o qual consegue manter a aliança com Roma porque não tinha sido perturbado por ambições ou paixões (XXIV.28.27). 
É bem provável que todos eles tenham influenciado o jovem tirano, mas é possível que ele de fato desejasse uma aliança com Cartago não só para se manter no trono, mas também para alargar seus domínios. De acordo tanto com Políbio quanto com Lívio, a decisão de romper o tratado com Roma e aliar-se a Cartago é tomada na corte. A plebe não tem participação.

Para o período após a morte de Jerônimo, contamos apenas com Lívio. Hipócrates e Epicides, então, entram em cena. Ambos começam a mobilizar os soldados, os desertores e pessoas da infima plebs contra o senado e os optimates no momento em que os praetores iniciavam as negociações para restabelecer a aliança com Roma. Adranodoro procurou se aproveitar da multitudo cada vez maior mobilizada pelos irmãos para pôr em prática os planos de sua conjura, pois via, na aliança com Cartago, uma possibilidade de assumir o poder.

Epicides e Hipócrates foram eleitos praetores pela multitudo e os soldados. Começam, então, as turbulências em Siracusa, mas ainda não podemos assumir que havia um sentimento anti-romano dominante na cidade. É somente depois da tomada de Leontini pelos romanos que os irmãos, com mentiras e talvez com a violência, conseguem mobilizar quase todos os siracusanos contra Roma. Tanto o uolgus quanto os senadores acreditam nas falsas notícias. A esta altura, todo o exército e a maior parte da plebe e dos principais são favoráveis a Epicides e Hipócrates, enquanto que os praetores, poucos dos optimates e a iuuentus popularium permanecem filoromanos. Os soldados e os desertores desde o início da ação dos irmãos Ihes foram favoráveis, talvez por interesses econômicos e militares.

Lívio teria identificado a multitudo, termo sempre usado de maneira negativa, com os seguidores de Hipócrates e Epicides como um modo de desacreditar as atitudes dos irmãos. Eles conseguiriam persuadi-la por causa de sua volubilidade e irracionalidade. A razão levaria a apoiar Roma, a mentira e a loucura a apoiar Cartago.

Diante dos eventos de Siracusa tais quais narrados por Políbio e Lívio, não podemos afirmar que houvesse nítida distinção social entre os partidos filo-romano e filo-cartaginês. Além disso, ambições políticas, oportunismo e sentimentos locais foram os elementos que determinaram a decisão de uma aliança ora com Roma, ora com Cartago. A filiação a uma ou a outra parte não foi instantânea e gratuita, mas decidida após discussões, reflexões e eventos delicados. Embora, com os dados que temos, não possamos confrontar totalmente a tese de Fustel de Coulanges podemos ao menos nuançá-la. 